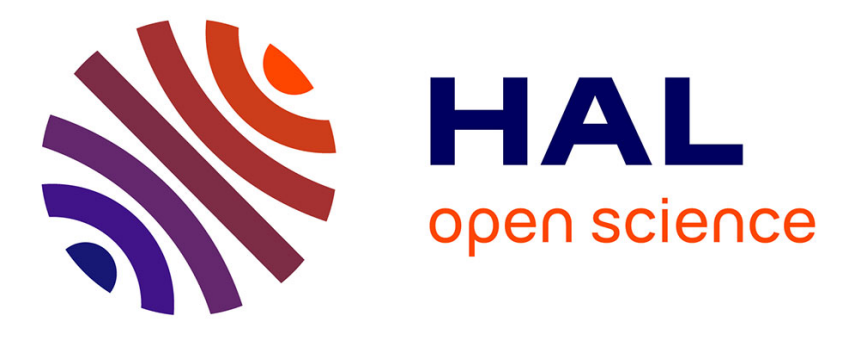

\title{
In vitro performance assessment of new beta $\mathrm{Ti}-\mathrm{Mo}-\mathrm{Nb}$ alloy compositions
}

\author{
Patricia Neacsu, Doina-Margareta Gordin, Valentina Mitran, Thierry \\ Gloriant, Marieta Costache, Anisoara Cimpean
}

\section{- To cite this version:}

Patricia Neacsu, Doina-Margareta Gordin, Valentina Mitran, Thierry Gloriant, Marieta Costache, et al.. In vitro performance assessment of new beta Ti-Mo-Nb alloy compositions. Materials Science and Engineering: C, 2015, 47, pp.105-13. 10.1016/j.msec.2014.11.023 . hal-01153416

\section{HAL Id: hal-01153416 \\ https://hal-univ-rennes1.archives-ouvertes.fr/hal-01153416}

Submitted on 21 Oct 2015

HAL is a multi-disciplinary open access archive for the deposit and dissemination of scientific research documents, whether they are published or not. The documents may come from teaching and research institutions in France or abroad, or from public or private research centers.
L'archive ouverte pluridisciplinaire HAL, est destinée au dépôt et à la diffusion de documents scientifiques de niveau recherche, publiés ou non, émanant des établissements d'enseignement et de recherche français ou étrangers, des laboratoires publics ou privés. 


\title{
In vitro performance assessment
}

\section{of new beta Ti-Mo-Nb alloy compositions}

\author{
Patricia Neacsu $^{\mathrm{a}}$, Doina-Margareta Gordin ${ }^{\mathrm{b}}$, Valentina Mitran ${ }^{\mathrm{a}}$, \\ Thierry Gloriant $^{\mathrm{b}}$, Marieta Costache ${ }^{\mathrm{a}}$, Anisoara Cimpean ${ }^{\mathrm{a}, ~ *}$
}

${ }^{a}$ University of Bucharest, Department of Biochemistry and Molecular Biology, 91-95 Spl. Independentei, 050095, Bucharest, Romania

${ }^{b}$ INSA Rennes, UMR CNRS 6226 ISCR/Chimie-Métallurgie, 20 avenue des Buttes de Coësmes, F-35043 Rennes Cedex, France

${ }^{*}$ Corresponding author:

E-mail address: anisoara.cimpean@bio.unibuc.ro

Tel.: +40 21 3181575/106; Fax: +40 21 3181575/ 102

University of Bucharest, Department of Biochemistry and Molecular Biology, 91-95 Spl. Independentei, 050095, Bucharest, Romania 
ABSTRACT. New $\beta$-titanium based alloys with low Young's modulus are currently required for the next generation of metallic implant materials to ensure good mechanical compatibility with bone. Several of these are representatives of the ternary Ti-Mo-Nb system. The aim of this paper is to assess the in vitro biological performance of five new low modulus alloy compositions, namely Ti12Mo, Ti4Mo32Nb, Ti6Mo24Nb, Ti8Mo16Nb and Ti10Mo8Nb. Commercially pure titanium (cpTi) was used as a reference material. Comparative studies of cell activity exhibited by MC3T3-E1 pre-osteoblasts over short- and long-term culture periods demonstrated that these newly-developed metallic substrates exhibited an increased biocompatibility in terms of osteoblast proliferation, collagen production and extracellular matrix mineralization. Furthermore, all analyzed biomaterials elicited an almost identical cell response. Considering that macrophages play a pivotal role in bone remodeling, the behaviour of a monocyte-macrophage cell line, RAW 264.7, was also investigated showing a slightly lower inflammatory response to Ti-Mo-Nb biomaterials as compared with cpTi. Thus, the biological performances together with the superior mechanical properties recommend these alloys for bone implant applications.

Key words: beta titanium alloys; Ti-Mo-Nb; pre-osteoblast; differentiation; macrophage; inflammatory response. 


\section{Introduction}

Nowadays, the strategies in the design of orthopedic implants try to create biomaterials with a low Young modulus in order to inhibit the stress shielding effect that occurs at the bone-implant interface. This phenomenon is associated with bone atrophy, weakness at the interface between the implant and the host tissue and, ultimately, premature rejection of the implant [1]. $\beta$ - Type titanium (Ti) alloys represent some of the most attractive biomaterials due to their superior mechanical properties and biocompatibility, including a low elastic modulus and good plasticity [2]. Therefore, from mechanical compatibility perspective, $\beta$-Ti alloys are more suitable for biomedical applications than conventional materials used as hard tissue substituents. On the other hand, the presence of potentially toxic elements in the commonly used metallic biomaterials such $\mathrm{Ni}, \mathrm{Al}, \mathrm{V}$ must be avoided for the next generation of implantable materials. Consequently, attempts have been made to replace them with other non-toxic elements in order to enhance the safety of biomedical implants. Non-toxic $\beta$ stabilizers like $\mathrm{Nb}, \mathrm{Mo}, \mathrm{Ta}, \mathrm{Zr}, \mathrm{Sn}$, etc. were selected for designing new $\beta$-type Ti-based alloys with lower elastic modulus, greater strength and corrosion resistance [3]. In recent years, various low modulus $\beta$-type Ti-based alloys, among which Ti-Mo [4, 5], Ti-Nb [6-9], and the ternary Ti-Mo-Nb or Ti-Ta-Nb [3, 10-15], were elaborated. As alloying element, $\mathrm{Nb}$ is well known to exhibit a very good resistance against corrosion in simulated body fluid and excellent biocompatibility $[16,17]$. The use of Mo is somewhat controversial [18] but some studies have demonstrated adequate mechanical compatibility and good cytocompatibility of Ti-alloys containing Mo such as Ti-Mo, Ti-Mo-Ta or Ti-Mo-Zr-Fe [19-23]. The advantage of using Mo is that this element has strong $\beta$-stabilizing properties on Ti alloys in comparison with $\mathrm{Nb}$, Ta or $\mathrm{Zr}$ elements and the synthesis of $\beta$-Ti alloys containing Mo is then easier. 
There is a scarce literature concerning biological activity of $\beta$-Ti alloys containing Mo and/or $\mathrm{Nb}$ in various ratios or in addition to other non-toxic elements. For example, Junior et al. [23] showed that binary Ti-15Mo alloy did not elicit any cytotoxic effect and did not cause interference in the cellular growth or viability of MC3T3-E1 pre-osteoblasts. Likewise, Ti$16 \mathrm{Nb}$ alloy proved to have an excellent biocompatibility exhibiting high proliferation rate of L929 cells [7], oxidized Ti-Nb alloy increased the proliferation rate of MG-63 osteoblasts [24] and the porous Ti-Nb supported the rabbit bone marrow mesenchymal stem cell adhesion and growth with no obvious inflammatory response [25]. Moreover, Wu [26] assessed the in vitro and in vivo biological responses of a new $\beta$-Ti Mo alloy, namely Ti9.7Mo-4Nb-2V-3Al. This alloy exhibited good biocompatibility with respect to cytotoxicity, acute irritation, systemic toxicity, rabbit pyrogen, indirect and direct contact hemolysis and short-term implantation, based on ISO 10993 recommended for material screening.

In this paper, we study the in vitro biocompatibility of a group of five new biomedical beta Ti-based alloys: Ti12Mo, Ti4Mo32Nb, Ti6Mo24Nb, Ti8Mo16Nb and Ti10Mo8Nb. These alloys demonstrated excellent mechanical properties such as low modulus at around 80 $\mathrm{GPa}$, high strain hardening reaching a maximum value close to $2000 \mathrm{MPa}$, large plastic deformation and good ductility since around $40 \%$ of elongation at rupture was obtained [27]. Bone cell biocompatibility was investigated on mouse MC3T3-E1 pre-osteoblastic cell line and the evaluation of the inflammatory response generated by these surfaces was performed on murine RAW 264.7 macrophage cell line. Osteoblast response was evaluated in terms of cell adhesion and proliferation, as well as morphological characteristics and cell differentiation. Also, the inflammatory response was assessed mainly by the quantification of some pro-inflammatory mediators secreted in the culture medium, namely TNF- $\alpha$ (tumor necrosis factor- $\alpha$ ), RANTES (Regulated upon Activation Normal T cell Expressed and Secreted) and MIP-1 $\alpha$ (macrophage inflammatory protein-1 $\alpha)$. 


\section{Experimental}

\subsection{Alloy preparation and characterization}

The five studied alloy composition were synthesized by the cold crucible levitation melting (CCLM) technique in a CELES induction furnace under a pure Ar atmosphere, which was introduced after several cycles of high vacuum pumping. Ingots of about $20 \mathrm{~g}$ were thus obtained by this melting process. After melting, the ingots were annealed in the $\beta$-phase domain under high vacuum $\left(10^{-7} \mathrm{mbar}\right)$ at $950^{\circ} \mathrm{C}$ for $20 \mathrm{~h}$ in order to homogenize the microstructure due to the thermal gradient occurring during solidification and then water quenched. The ingots were cold rolled $(\mathrm{CR}=90 \%)$ and machined to obtained biological test samples (discs of $13 \mathrm{~mm}$ diameter and $1 \mathrm{~mm}$ thickness). All samples were finally solution treated at $850^{\circ} \mathrm{C}$ for 30 minutes and water quenched in order to restore a fully recrystallized metastable $\beta$-microstructure from the cold-rolled state.

X-ray diffraction (XRD) was used to check that the elaborated alloys well present the $\beta$-phase microstructure required. The measurements were performed at room temperature with a Philips PW 1830/00 diffractometer with $\mathrm{CuK}_{\alpha 1}$ radiation $(\lambda=1.54060 \AA)$.

In this study, the commercially pure titanium (cpTi) was used as reference for the biological tests (GoodFellow supplier). In order to eliminate the effects of surface topography on cell behaviour, all the tested samples were mechanically polished on silicon carbide abrasive papers using an automatic polishing system (Struers). The polished samples were cleaned by immersion for $30 \mathrm{~min}$ in alcohol and $30 \mathrm{~min}$ in distilled water using an ultrasonic cleaner (Geoson LD-050).

The roughness of the samples was evaluated using a conventional confocal microscope (CHR 150N, Stil) in "distance" mode. For each alloy, 10 measurements were obtained from 
200x200 $\mu \mathrm{m}$ areas in different zones of the 12 samples. From these measurements, an average roughness value, Ra, was evaluated ( \pm standard deviation) for each alloy.

\subsection{In vitro study design}

The biological activities elicited by the contact with the alloy surfaces in bone healing cells and macrophages involved in the inflammatory cascade, were studied by using MC3T3E1, subclone 4 (a mouse pre-osteoblast cell line exhibiting behaviour similar to primary calvarial osteoblasts) and RAW 264.7 (a monocyte-macrophage cell line widely used for inflammation studies) (both provided by American Type Culture Collection). Both cell lines were grown in Dulbecco's Minimal Essential Medium supplemented with 10\% foetal bovine serum and $1 \%$ penicillin/streptomycin and were incubated, for specific time periods, at $37^{\circ} \mathrm{C}$ in a humidified atmosphere with 5\% $\mathrm{CO}_{2}$. MC3T3-E1 pre-osteoblasts were seeded on metal surfaces, placed in 12-well plates, at a density of $10^{4}$ cells $\cdot \mathrm{cm}^{-2}$ for the experiments regarding cell adhesion, the degree of spreading, morphology and cellular proliferation, while RAW 264.7 macrophages were seeded at a density of $5 \times 10^{4}$ cells $\cdot \mathrm{cm}^{-2}$ for enzyme-linked immunosorbent assay (ELISA) studies or $1.5 \times 10^{5}$ cells $\cdot \mathrm{cm}^{-2}$ for the evaluation of cell morphology, in two different culture conditions: non-inflammatory and pro-inflammatory (stimulation with $10 \mathrm{ng} \cdot \mathrm{mL}^{-1}$ lipopolysaccharide, LPS).

\subsection{Evaluation of cytotoxicity}

Possible cytotoxic effects of the tested substrates were evaluated in the case of MC3T3E1 pre-osteoblasts by analyzing the activity of lactate dehydrogenase (LDH) released into the culture medium as a marker of cell death and lysis of the plasma membrane. The study was carried out in triplicate in the cell culture medium, kept in contact with the Ti-based materials for $48 \mathrm{~h}$, by using a cytotoxicity detection kit (Tox-7, Sigma-Aldrich) according to the 
manufacturer's protocol. Absorbance was evaluated at $490 \mathrm{~nm}$ using a microplate reader (Thermo Scientific Appliskan).

\subsection{Cell viability and proliferation}

The viability of MC3T3-E1 and RAW 264.7 cells was assessed at 1-, 3-, 5- and 1-, 2days post-seeding, respectively. This study was performed using tetrazolium dye (MTT) colorimetric assay, as previously reported [28].

\subsection{Fluorescent labelling of actin and vinculin}

The pre-osteoblast cells grown on Ti-based alloys for $15 \mathrm{~min}, 30 \mathrm{~min}, 2 \mathrm{~h}$ and $24 \mathrm{~h}$, were fixed with $4 \%$ paraformaldehyde, permeabilized and blocked with $0.1 \%$ Triton X$100 / 2 \%$ bovine serum albumin for $1 \mathrm{~h}$ and, subsequently, washed with phosphate buffered saline (PBS). The samples were then incubated with anti-vinculin antibody (Santa Cruz Biotechnology) for $2 \mathrm{~h}$ at room temperature, washed again with PBS and incubated for $1 \mathrm{~h}$ with a specific secondary antibody coupled with Alexa Fluor 488. Subsequently, it was added phalloidin coupled with Alexa Fluor 546, to label actin filaments, and DAPI (4'6-diamidino2-phenylindole) to visualize the nuclei. The macrophage morphology studies were performed by labeling the actin cytoskeleton with Alexa Fluor 488-phalloidin. Labeled samples were washed 3 times with PBS and examined under an inverted microscope equipped with epifluorescence (Olympus IX71). The microscopic images were captured using the Cell F software.

\subsection{Evaluation of the extracellular matrix mineralization}

To evaluate the differentiation potential, pre-osteoblasts were seeded at a density of $5 \mathrm{x}$ $10^{4}$ cells $/ \mathrm{cm}^{2}$ in the culture conditions previously reported [28]. Cell differentiation was 
assessed at 4- and 6- weeks post-seeding by Alizarin red staining of calcium deposits [28] and by Sirius Red staining of type I collagen. The formed collagen matrix was identified by Sirius Red (Bio-optica) staining of fixed specimens with 10\% formaldehyde solution (for 20 min), followed by its solubilization in a sodium hydroxide:methanol (1:1) solution. The absorbance of resulted solution was read at $405 \mathrm{~nm}$ using a microplate reader (Thermo Scientific Appliskan).

\subsection{Extracellular cytokine and chemokine analysis}

The concentrations of TNF- $\alpha$, MIP- $1 \alpha$ and RANTES that were secreted in the culture medium were determined by ELISA technique (R\&D Systems) according to package insert instructions. The levels of secreted cytokine/chemokines were measured in supernatants harvested at 24- and 48-h post-seeding. To eliminate variations due to the differences in cell viability, secreted cytokine and chemokines were expressed in relation to the number of cells that grew in contact with the control sample, according to the results of the MTT assay. Concentrations of the analyzed cytokine and chemokines were calculated as follows: normalized $\mathrm{pg} / \mathrm{ml}=$ measured $\mathrm{pg} / \mathrm{ml}$ x (control cells MTT OD/sample cells MTT OD).

\subsection{Statistical analysis}

Statistical analysis was performed using one-way ANOVA with Bonferroni's multiple comparison tests. All values are expressed as mean value \pm standard deviation (SD) of three independent experiments and differences at $\mathrm{p}>0.05$ were considered statistically insignificant.

\section{Results}

\subsection{Alloy characterization}


As presented in Fig. 1A, all five alloy compositions were found to be in a fully $\beta$ microstructural state (body centred cubic structure) by XRD analysis. Indeed, each peak can be well indexed with this crystallographic structure and the related diffracted planes are indicated on the diffractograms.

After polishing, all samples used for the biological tests have the same morphology, with a $0.75 \pm 0.05 \mu \mathrm{m} \mathrm{R}_{\mathrm{a}}$ roughness value. Fig. 1B illustrates a typical morphology, characteristic for all alloys obtained by confocal microscopy.

\subsection{MC3T3-E1 pre-osteoblast behaviour}

\subsubsection{Cell viability and proliferation}

The effects of the newly-developed Ti-Mo-Nb alloys on pre-osteoblast cell viability were studied by quantifying the amount of cytoplasmic LDH released from the damaged cells and the mitochondrial dehydrogenases from the viable cells as biocompatibility markers for cell-biomaterial interaction. As it is clear from Fig. 2A, the cells grown on the alloy surfaces showed low levels of LDH released in the culture medium at all studied time points. There were no statistically significant differences between Ti-alloys and the reference material. It can also be noticed an increase in the amount of LDH released by the MC3T3-E1 cells over incubation time. This increase is not a significant one for the substrate-induced cytotoxicity and could be explained by the cell death that could appear as the monolayer confluence proceeds and by a longer cell incubation time. The MTT assay indicates that the number of metabolically active cells is increasing with the incubation period (Fig. 2B). Moreover, no significant differences between the optical density (OD) values obtained for cells grown on Ti-Mo-Nb alloys and between these and the reference biomaterial were remarked at any time point. 


\subsubsection{Cell attachment and morphological features}

Cell adhesion and morphology were both investigated in this study to further confirm the biocompatibility of these Ti-alloys in an in vitro environment. Fluorescence microscopy was used in order to assess the cell attachment, spreading and morphological features. Concomitant labeling of actin and vinculin was used to evaluate the cell attachment and cytoskeleton organization in pre-osteoblasts grown on the analyzed substrates for $15 \mathrm{~min}, 30$ min, $2 \mathrm{~h}$ and $24 \mathrm{~h}$ (Fig. 3). It can be seen that, after $15 \mathrm{~min}$ of culture (Fig. 3A), the cells were in the process of spreading on the metallic substrates. Cortical actin bundles predominantly appeared at the peripheries of cells, consistent with a less-spreading and rounded up morphology. At 30 min post-seeding, the cell area increased, the actin filaments were still localized in the peripheral regions of the cells but immunoreactive sites for vinculin, showing a punctiform pattern which suggests the formation of focal adhesions between plasma membrane and extracellular proteins adsorbed to biomaterial surfaces, appeared in some cells (Fig. 3B). This pattern of vinculin staining was more evident at $2 \mathrm{~h}$ after cell plating (Fig. 3C) when the cells attained a well spread morphology on all analyzed metallic substrates, suggesting that they equally support cell adhesion. MC3T3-E1 cells cultured for $24 \mathrm{~h}$ (Fig. 3D) assumed an elongated, spindle-shaped appearance typical for osteoblast-like cells and exhibited prominent actin stress fibers that appeared to be arranged parallel to the long axis of the cell. Furthermore, immunoreactive sites for vinculin, displaying punctiform pattern, were found predominantly at the termini of actin microfilament bundles. This indicates that all five newly-developed surfaces exhibit greatest amount of adhesion with no difference in adhesion pattern, and also showed very similar patterns with the reference material, cpTi. Further, no differences in cell morphology and number were observed and there was no evidence of membrane damage, cytoplasmic vacuolation or cell death. 


\subsubsection{Pre-osteoblast differentiation and mineralization of extracellular matrix}

We further evaluated the long-term response of osteoblast grown in contact with the TiMo-Nb alloys and cpTi with regard to the osteoblast differentiation and matrix mineralization potential, in the abscence or presence of the osteogenic cell culture supplements $\left(50 \mu \mathrm{g} \cdot \mathrm{mL}^{-1}\right.$ ascorbic acid and $5 \mathrm{mM}$ beta-glycerophosphate). Cell differentiation was assessed after 4 and 6 weeks of culture, a time period required by the cells to display evidence of maturation. For detection of matrix calcification, Alizarin Red staining was performed, and collagen was quantified by staining with Sirius Red. We found out a significant increase in matrix mineralization when MC3T3-E1 cells were cultured in the differentiation-inducing media comparative with unstimulated pre-osteoblasts, both at 4 and 6 weeks post-seeding (Fig. 4A). Furthermore, a time-dependent increase in OD values was remarked for both culture conditions and no significant differences between the analyzed substrates were found. The same trend was noticed with regard to total collagen synthesis (Fig. 4B). Consequently, the tested metallic surfaces appeared to have no differential effects on either the quantity of calcium deposits (Fig. 4A) or the extent of collagen formation (Fig. 4B), being able to equally support the pre-osteoblast differentiation.

\subsection{RAW 264.7 macrophage behaviour}

In order to assess the biological activity of RAW 264.7 macrophages in contact with the Ti-Mo-Nb alloys in terms of adhesion and proliferation ability, we concomitantly used a qualitative method which allowed fluorescent visualization of actin cytoskeleton and a quantitative assay, MTT, which measured cell proliferation rate. RAW 264.7 cells were maintained in culture for up to $48 \mathrm{~h}$ in the presence or absence of LPS, an outer membrane component of Gram-negative bacteria which can initiate a potent inflammatory response. As regards the cell density and proliferation, the OD values were very similar for all Ti- based 
alloys with a slight decrease on cpTi, in both culture conditions (Fig. 5B). Fluorescence microscopy images (Fig. 5A) reveal a uniform population of cells with round appearance on all analyzed surfaces. However, in the pro-inflammatory conditions, round cells with increased cell area as well as cells displaying an elongation tendency were remarked. These observations suggest that all tested biomaterials have the ability to equally support the adhesion and growth of macrophages. Subsequently, we analyzed the levels of proinflammatory cytokine TNF- $\alpha$ and chemokines MIP- $1 \alpha$ and RANTES released into the culture medium after $24 \mathrm{~h}$ and $48 \mathrm{~h}$ of culture in both standard and pro-inflammatory conditions. As shown in Fig. 6, macrophages grown on all studied alloys displayed very similar levels of cytokine/chemokine secretion with a slight increase, but not a significant one, on the cpTi. Furthermore, these pro-inflammatory mediators recorded a significant increase when macrophages were stimulated with LPS. It should be also noted that cytokine/chemokine levels demonstrated a time dependent reduction suggesting the absence of a persistent inflammatory response. This decrease was more prominent in LPS-stimulation conditions for all analyzed pro-inflammatory molecules.

\section{Discussion}

Osteoblasts and macrophages are key cells involved in the implant osseointegration process. Hence, evaluation of their behaviour on potential biomaterials may provide insight into their biocompatibility. In this study, we have investigated the in vitro biological performance of newly-developed alloy compositions in the ternary Ti-Mo-Nb system. The first objective of the study was to assess in vitro short-term biocompatibility of these alloys in comparison with cpTi. Thus the results of LDH and MTT assays indicated that all five Tialloys surfaces exhibited no cytotoxic effects on MC3T3-E1 cells, being able to support the 
normal cell growth and proliferation, in a very similar manner with the reference material. Besides cytotoxicity and proliferation rate, an important issue of cell response to the biomaterial surface is cell adhesion. In vivo, metallic implants are subjected to fibrous encapsulation which is known to occur following inadequate cell adhesion to their surface, resulting in the implant destabilization as well as an inhibition of tissue regeneration and repair [29]. Thus the consequences of impaired cell adhesion are the rejection and failure of the implant. In this study, we have investigated one of the primary mechanisms of cell adhesion, namely the formation of focal contacts. Focal contacts consist of a variety of molecules that link the actin cytoskeleton to the external environment, allowing the cell to adapt to the surface. Vinculin is a membrane-cytoskeletal protein in focal adhesions associated with cell-cell and cell-matrix junctions [30]. Therefore, this integral focal adhesion protein is ideal for the assessment of cell adhesion to the substrate due to the fact that it appears within 3 hours of cell attachment [31]. We could detect immunoreactive sites for vinculin, showing a punctiform pattern which suggests the formation of focal adhesions, especially at $2 \mathrm{~h}$ and $24 \mathrm{~h}$ post-seeding. Consequently, all analyzed surfaces favored cell adhesion to equivalent extents. Further, the morphological features of the osteoblasts evaluated in terms of the degree of cell spreading as well as an estimation of cell shape, were used as a mean for comparing the effects of Ti-Mo-Nb alloys and cpTi. In the fluorescence microscopy images we observed a progressive spreading of the cells towards an elongated, spindle-shaped appearance which is typical for osteoblast-like cells. Furthermore, a highly organized cytoskeleton with classical stress fibers could be remarked, aspect that is often associated with strong osteoblast adhesion. Hence, the short-term in vitro osteoblast response proved that all tested surfaces sustained a normal cellular morphology with high number of focal adhesion sites anchoring the cells to the metallic substrates. 
On implantation in a living body, biomaterials have the potential to elicit an immune response that can either sustain regeneration or lead to fibrosis in case of an aggravated inflammation [32]. Early presence of macrophages at the biomaterial implantation site is critical for a normal healing of the surrounding tissue after injury [33]. Thus, the behaviour of macrophages can increase, decrease or redirect the inflammatory and subsequent healing processes associated with the presence of a biomaterial [34]. In our study, the MTT assay results and the fluorescent images show that the newly developed Ti-Mo-Nb alloys are able to sustain the survival and proliferation of macrophages. Moreover, RAW 264.7 cells grown on these substrates exhibited a normal cell growth and morphology. Thus, in standard culture conditions, they assumed a typical rounded morphology but in the LPS-stimulation conditions they became bigger and displayed a ruffled membrane. As compared with MC3T3-E1 cells, which displayed highly organized and aligned actin fibers, the macrophages exhibited mainly a difuse actin staining. As Owen et al. [35] stated, macrophages are motile cells that form small focal complexes rather than large focal adhesions and produce fine actin cables rather than stress fibers. They are key players during the initial phase of bone healing and remodeling [36]. During this phase, macrophages secrete various cytokines, chemokines and growth factors that contribute to pushing the wound healing process into the next phase [37]. While it is clear that the biomaterial surface can have a profound effect on the inflammatory response, the secretion of these molecules in high amounts may lead to inflammatory osteolysis and implant instability [38]. Our data show that macrophages on all surfaces released low amounts of pro-inflammatory cytokines in standard culture conditions. Moreover, the amount of pro-inflammatory factors decreased from $24 \mathrm{~h}$ to $48 \mathrm{~h}$. These studies confirm the fact that RAW 264.7 cells were slightly activated and do not promote a prolonged inflammation in contact with the tested substrates. However, a higher degree of activation occurred under LPS treatment. 
Finally, the most important goal in biomaterials research is the substrate ability to support the development of progenitor cells into functional tissues. The long-term outcome of metallic implants should result in the formation of a characteristic interfacial layer and bone matrix with appropriate biomechanical properties. The formation of a mineralized matrix during implant osseointegration involves recruitment of multipotent mesenchymal stem cells and their progressive differentiation into osteoblasts [39]. In this context, we have investigated the effects of the five analyzed surfaces on the pre-osteoblast differentiation into mature cells and on matrix mineralization potential. We found out that all studied alloys allowed cell differentiation to occur on their surfaces. Thus, calcium deposits and type I collagen were formed in increasing amounts from 4 to 6 weeks. Importantly, the expression of these bone markers was higher under osteogenic stimulated conditions. These results suggest that the novel $\beta$-type Ti-Mo-Nb alloys could support the osteogenic activity at the interface of the implant with bone.

As regards the critical biological responses for implant performance, in the literature are presented very few papers that investigate the differentiation potential or the inflammatory reactions that could occur in response to $\beta$-Ti based alloys. For example, a recent study [28] has aimed to evaluate the pre-osteoblast and macrophage responses induced by a novel $\beta$-type alloy, Ti-23Nb-0.7Ta-2Zr-0.5N, as compared with Ti-6Al-4V. The results obtained indicated that the newly-developed alloy was significantly more efficient in supporting mineralized matrix deposition upon osteogenic induction than the reference material. Also, the analysis of cytokine gene and protein expression profiles in RAW 264.7 macrophages indicated no significant inflammatory response. Another recent study [40] investigated three different compositions in Ti-Nb-Zr-Ta (A1, A2 and A3) by performing in vivo biocompatibility tests on Wistar adult rats. Following intraosseous and subcutaneous implantation, the sample A1 showed an enhanced mineralization around the material and also 
a good biocompatibility regarding blood parameters. Likewise, TiMo12Zr6Fe2 (TMZF) alloy allowed the adhesion and proliferation of primary human fibroblasts and osteoblasts and also increased the amount of type I collagen as compared with plastic tissue culture dishes [20].

In this context, taken together all our observations with respect to the biological response of MC3T3-E1 and RAW 264.7 cells to the newly-developed Ti-Mo-Nb compositions it could be predicted that these metallic substrates can promote bone growth and implant osseointegration.

\section{Conclusion}

This in vitro research indicates that the new beta Ti-Mo-Nb alloy compositions lead to good biocompatibility. As we have shown, the developed $\beta$-type Ti-based alloys did not negatively impact on the adhesion, morphology, proliferation rate and differentiation potential of MC3T3-E1 pre-osteoblasts as compared to the reference biomaterial, cpTi. Moreover, no significant inflammatory response was elicited in RAW 264.7 macrophages grown on these alloys. In the context of biomaterials development for current bone implantology, these findings open new avenues towards the potential use of these innovative alloys for tissue regeneration purposes.

\section{Acknowledgements}

This study was financially supported by research grant from the Romanian Ministry of National Education, CNCS-UEFISCDI (project PNII-ID-PCE 188/2011). 


\section{References}

[1] M. Niinomi, Low modulus titanium alloys for inhibiting bone atrophy, in: R. Pignatello (Ed), Biomater. Sci. Eng., InTech, 2011, pp. 249-268.

[2] M. Niinomi, M. Nakai, Titanium-based biomaterials for preventing stress shielding between implant devices and bone, Int. J. Biomater., 2011 (2011) Article ID 836587.

[3] Y. Li, C. Yang, H. Zhao, S. Qu, X. Li, Y. Li, New developments of Ti-based alloys for biomedical applications, Materials 7 (2014) 1709-1800.

[4] X. Zhao, M. Niinomi, M. Nakai, J. Hieda, Beta type Ti-Mo alloys with changeable Young's modulus for spinal fixation applications, Acta Biomater. 8 (2012) 1990-1997.

[5] F.F. Cardoso, P.L. Ferrandini, E.S.N. Lopes, A. Cremasco, R. Caram, Ti-Mo alloys employed as biomaterials: Effects of composition and aging heat treatment on microstructure and mechanical behavior, J. Mech. Behav. Biomed. Mater. 32 (2014) 31-38.

[6] H.Y. Kim, H. Satoru, J. Kim, H. Hosoda, S. Miyazaki, Mechanical properties and shape memory behavior of Ti-Nb alloys, Mater. Trans. 45 (2004) 2443-2448.

[7] Y.B. Wang, Y.F. Zheng, Corrosion behaviour and biocompatibility evaluation of low modulus Ti-16Nb shape memory alloy as potential biomaterial, Mater. Lett. 63 (2009) 12931295.

[8] B.L. Wang, L. Li, Y.F. Zheng, In vitro cytotoxicity and hemocompatibility studies of Ti$\mathrm{Nb}$, Ti-Nb-Zr and Ti-Nb-Hf biomedical shape memory alloys, Biomed. Mater. 5 (2010) 044102.

[9] A. Ramarolahy, P. Castany, F. Prima, P. Laheurte, I. Peron, T. Gloriant, Microstructure and mechanical behavior of superelastic Ti-24Nb-0.5O and $\mathrm{Ti}-24 \mathrm{Nb}-0.5 \mathrm{~N}$ biomedical alloys, J. Mech. Behav. Biomed. Mater. 9 (2012) 83-90. 
[10] L.J. Xu, Y.Y. Chen, Z.G. Liu, F.T. Kong, The microstructure and properties of Ti-Mo$\mathrm{Nb}$ alloys for biomedical application, J. Alloy Compd. 453 (2008) 320-324.

[11] E. Bertrand, T. Gloriant, D.M. Gordin, E. Vasilescu, P. Drob, C. Vasilescu, S.I. Drob, Synthesis and characterization of a new superelastic Ti-25Ta-25Nb biomedical alloy, J. Mech. Behav. Biomed. Mater. 3 (2010) 559-564.

[12] P. Laheurte, F. Prima, A. Eberhardt, T. Gloriant, M. Wary, E. Patoor, Mechanical properties of low modulus $\beta$ titanium alloys designed from the electronic approach, J. Mech. Behav. Biomed. Mater. 3 (2010) 565-573.

[13] S.B. Gabriel, J. Dillec, C.A. Nunes, G. de Almeida Soare, The effect of Niobium content on the hardness and elastic modulus of heat-treated Ti-10Mo-XNb alloys, Mater. Res. 13 (2010) 333-337.

[14] Y. Al-Zain, H.Y. Kim, H. Hosoda, T.H. Namc, S. Miyazaki, Shape memory properties of Ti-Nb-Mo biomedical alloys, Acta Mater. 58 (2012) 4212-4223.

[15] C. Zhang, H. Tian, C. Hao, J. Zhao, Q. Wang, E. Liu, C. Dong, First-principles calculations of elastic moduli of Ti-Mo-Nb alloys using a cluster-plus-glue-atom model for stable solid solutions, J. Mater. Sci. 48 (2013) 3138-3146.

[16] Y. Okazaki, S. Rao, Y. Ito, T. Tateishi, Corrosion resistance, mechanical properties, corrosion fatigue strength and cytocompatibility of new $\mathrm{Ti}$ alloys without $\mathrm{Al}$ and $\mathrm{V}$, Biomaterials 19 (1988) 1197-1215.

[17] H. Matsuno, A. Yokoyama, F. Watari, M. Uo, T. Kawasaki, Biocompatibility and osteogenesis of refractory metal implants Ti, Hf, Nb, Ta, Rh, Biomaterials 22 (2001) 12531262.

[18] E. Eisenbarth, D. Velten, M. Müller, R. Thull, J. Breme, Biocompatibility of betastabilizing elements of titanium alloys, Biomaterials 25 (2004) 5705-5713. 
[19] W.F. Ho, C.P. Ju, L.J.H. Chern, Structure and properties of cast Ti-Mo alloys, Biomaterials 20 (1999) 2115-2122.

[20] L. Trentani, F. Pelillo, F.C. Pavesi, L. Ceciliani, G. Cetta, A. Forlino, Evaluation of the TiMo12Zr6Fe2 alloy for orthopaedic implants: in vitro biocompatibility study by using primary human fibroblasts and osteoblasts, Biomaterials 23 (2002) 2863-2869.

[21] D.M. Gordin, T. Gloriant, G. Texier, I. Thibon, D. Ansel, J.L. Duval, M.D. Nagel, Development of a $\beta$-type Ti-12Mo-5Ta alloy for biomedical applications: cytocompatibility and metallurgical aspects, J Mater. Sci. Mater. Med. 15 (2004) 885-891.

[22] S. Nag, R. Banerjee, H.L. Fraser, Microstructural evolution and strengthening mechanisms in Ti-Nb-Zr-Ta, Ti-Mo-Zr-Fe and Ti-15Mo biocompatible alloys, Mater. Sci. Eng. C 25 (2005) 357-362.

[23] J.R.S.M. Junior, A.R. Noguera, R. Oliveira de Araujo, T.A.G. Donato, V.E. AranaChavez, A.P.R.A. Claro, J.C.S. Moraes, M.A.R. Buzalaf, C.R. Gradini, Preparation and characterization of Ti-15Mo alloy used as biomaterial, Mat. Res. 14 (2011) 107-112.

[24] I. Jirka, M. Vandrovcova, O. Frank, Z. Tolde, J. Plsek, T. Luxbacher, L. Bacakova, and $\mathrm{V}$. Stary, On the role of $\mathrm{Nb}$-related sites of an oxidized $\beta$-TiNb alloy surface in its interaction with osteoblast-like MG-63 cells, Mater. Sci. Eng. C Mater. Biol. Applic. 33 (2013) 16361645.

[25] J. Xu, X.J. Weng, X. Wang, J.Z. Huang, C. Zhang, H. Muhammad, X. Ma, and Q.D. Liao, Potential use of porous titanium-niobium alloy in orthopedic implants: preparation and experimental study of its biocompatibility in vitro, PLoSONE (2013), DOI: 10.1371/journal.pone.0079289.

[26] M.H. Wu, Assessment of a superelastic beta TiMo alloy for Biomedical applications, in S. Shrivastava, (Ed.), Medical Device Materials: Proceedings of the Materials \& Processes for Medical Devices Conference, ASM International, 2004, pp. 343-348. 
[27] F. Sun, J.Y. Zhang, M. Marteleur, T. Gloriant, P. Vermaut, D. Laille, P. Castany, C. Curfs, P.J. Jacques, F. Prima, Investigation of early stage deformation mechanisms in a metastable $\beta$ titanium alloy showing combined twinning-induced plasticity and transformation-induced plasticity effects, Acta Mater. 61 (2013) 6406-6417.

[28] R. Ion, D.M. Gordin, V. Mitran, P. Osiceanu, S. Dinescu, T. Gloriant, A. Cimpean, In vitro bio-functional performances of the novel superelastic beta-type Ti-23Nb-0.7Ta-2Zr0.5N alloy, Mater. Sci. Eng. C Mater. Biol. Applic. 35 (2013) 411-419.

[29] L.C. Baxter, V. Frauchiger, M. Textor, I. ap Gwynn, R.G. Richards, Fibroblast and osteoblast adhesion and morphology on calcium phosphate surfaces, Eur. Cell. Mater. 4 (2002) 1-17.

[30] B. Geiger, Vinculin, in: Kreis, T., Vale, R. (Eds.), Guidebook to the extracellular Matrix, anchor and adhesion proteins, Oxford University Press, Oxford, 1999, pp. 92-95.

[31] M. Könönen, M. Hormia, J. Kwilahti, J. Hautaniemi, I. Thesleff, Effect of surface processing on the attachment, orientation and proliferation of human gingival fibroblasts on titanium, J. Biomed. Mater. Res. 26 (1992) 1325-1341.

[32] J.M. Anderson, Biological responses to biomaterials, Annu. Rev. Mater. Res. 31 (2001) $81-110$.

[33] L. He, A.G. Marneros, Macrophages are essential for the early wound healing response and the formation of a fibrovascular scar, Am. J. Pathol. 182 (2013) 2407-2417.

[34] M.B. Ariganello, D.T. Simionescu, R.S. Labowa, J.M. Lee, Macrophage differentiation and polarization on a decellularized pericardial biomaterial, Biomaterials 32 (2011) 439-449.

[35] K.A. Owen, F.J. Pixley, K.S. Thomas, M. Vicente-Manzanares, B.J. Ray, A.F. Horwitz, J.T. Parsons, H.E. Beggs, E.R. Stanley, A.H. Bouton, Regulation of lamellipodial persistence, adhesion turnover, and motility in macrophages by focal adhesion kinase, J. Cell. Biol. 179, (2007) 1275-1287. 
[36] A.C. Wu, L.J. Raggatt, K.A. Alexander, A.R. Pettit, Unraveling macrophage contributions to bone repair, BoneKEy Rep. 2 (2013) Article number: 373, DOI: 10.1038/bonekey.2013.107.

[37] P.M. Newton, J.A. Watson, R.G Wolowacz, E.J. Wood, Macrophages restrain contraction of an in vitro wound healing model, Inflammation 28 (2004) 207-214.

[38] H.G. Lee, A. Hsu, H. Goto, S. Nizami, J.H. Lee, E.R. Cadet., P. Tang, R. Shaji, C. Chandhanayinyong, S.H., Kweon, D.S. Oh, H. Tawfeek, F.Y.Lee, Aggravation of inflammatory response by costimulation with titanium particles and mechanical perturbations in osteoblast- and macrophage-like cells, Am. J. Physiol. Cell Physiol. 304 (2013) C431C439.

[39] J.E. Aubin, F. Liu, L. Malaval, A.K. Gupta, Osteoblast and chondroblast differentiation Bone 17 (1995) 77-83.

[40] L.A. Dragan-Raileanu, C. Munteanu, G.N. Basescu, C. Axinte, S.C. Strugaru, C. Papatoiu-Biniuc, A. Barbinta, Biocompatibility evaluation for some new Ti-Nb-Zr-Ta alloys, Annals of RSCB 18 (2013) 192-197. 


\section{Figure caption}

Fig. 1. X-ray diffraction patterns of the Ti-Mo-Nb alloys (A). Topographic confocal microscope images of the alloy surfaces: cpTi (B, left) and Ti-8Mo-16Nb alloy (B, right).
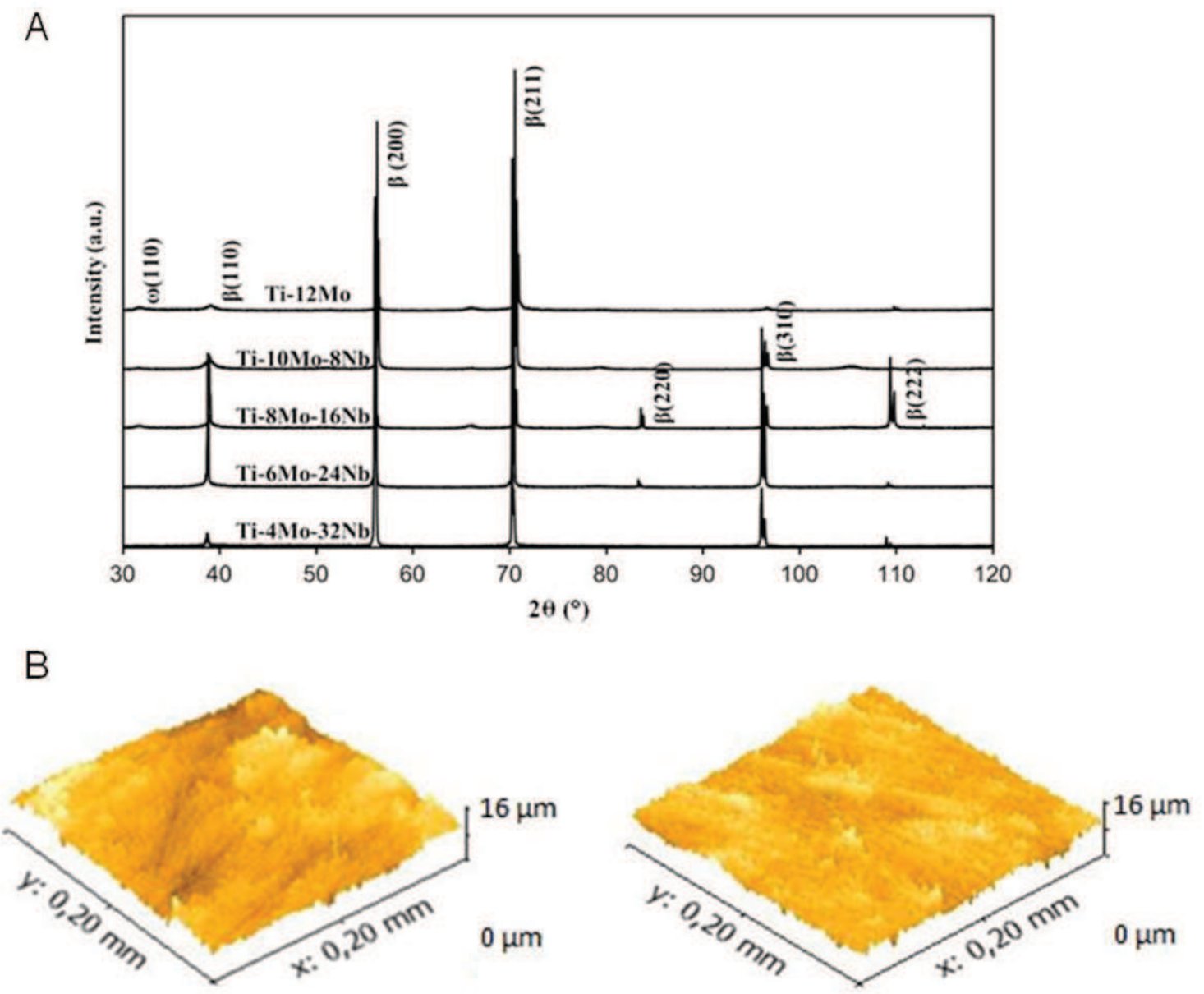
Fig. 2. Viability of MC3T3-E1 pre-osteoblasts grown in contact with cpTi and beta Ti-Mo$\mathrm{Nb}$ alloys for 1, 3 and 5 days, as determined by LDH (A) and MTT assays (B). Data analysis was based on mean $\pm \operatorname{SD}(n=3)$.

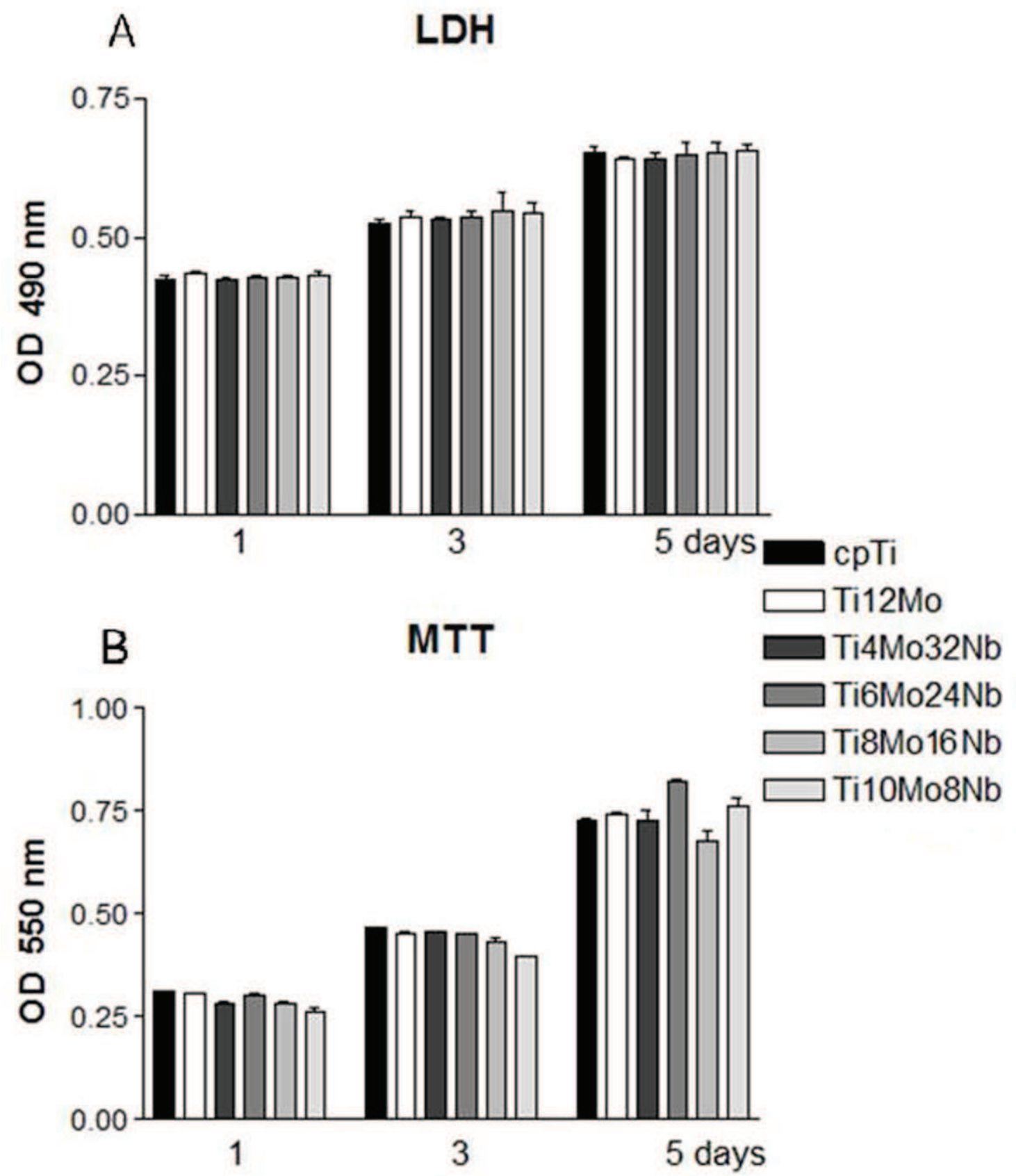


Fig. 3. Merged fluorescence images of actin filaments (red) and vinculin (green) in MC3T3E1 pre-osteoblasts grown on cpTi and Ti- based alloys from Ti-Mo-Nb system for: 15 min (A); $30 \mathrm{~min}(\mathrm{~B}) ; 2 \mathrm{~h}(\mathrm{C})$, and $24 \mathrm{~h}(\mathrm{D})$. The scale bar corresponds to $20 \mu \mathrm{m}$ length.
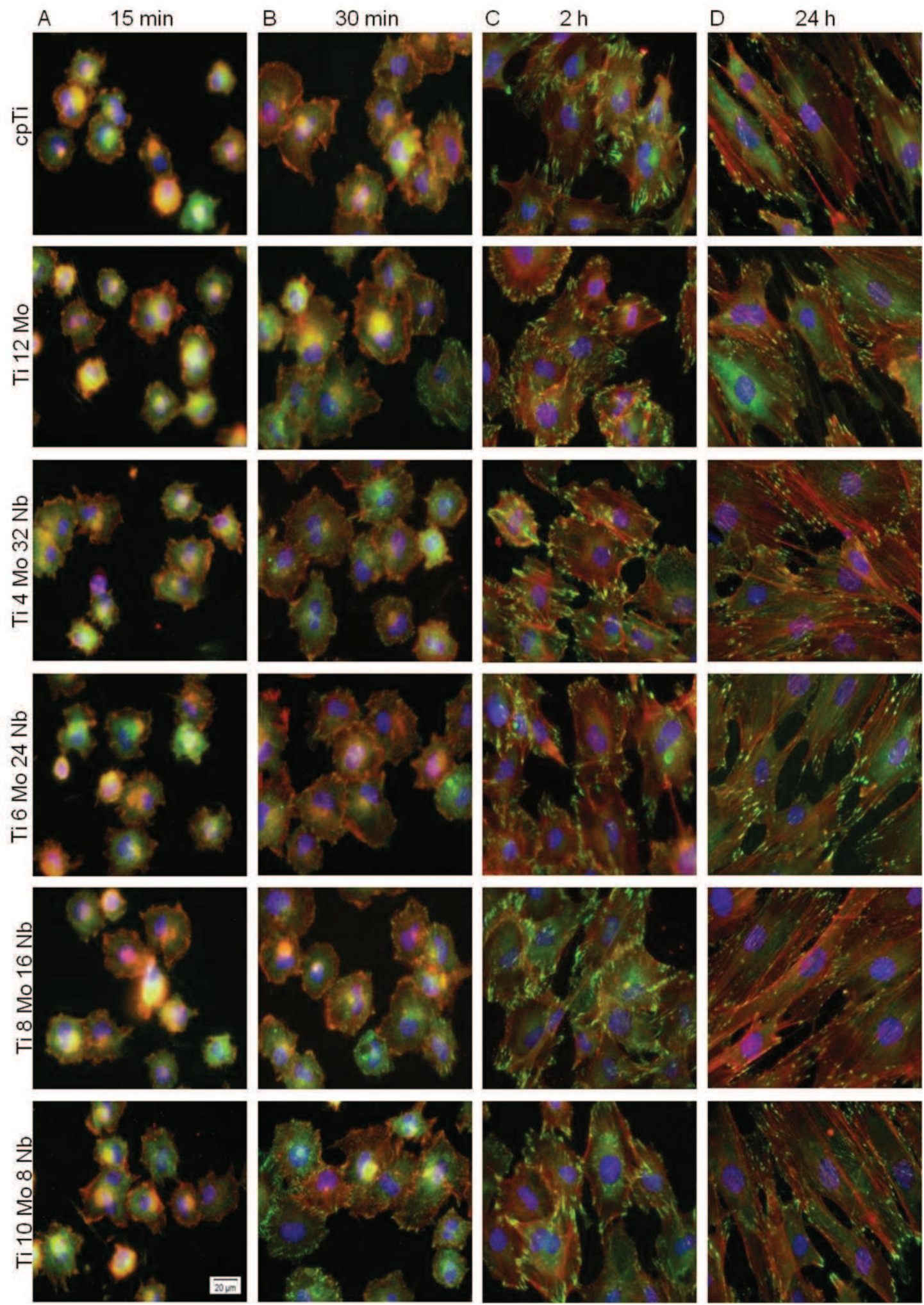
Fig. 4. Pre-osteoblast differentiation on cpTi and Ti- based alloys from Ti-Mo-Nb system, as assessed by the analysis of collagen synthesis (A), and extracellular matrix mineralization (B) after 4 and 6 weeks of culture. Data analysis was based on mean $\pm \operatorname{SD}(n=3)$.

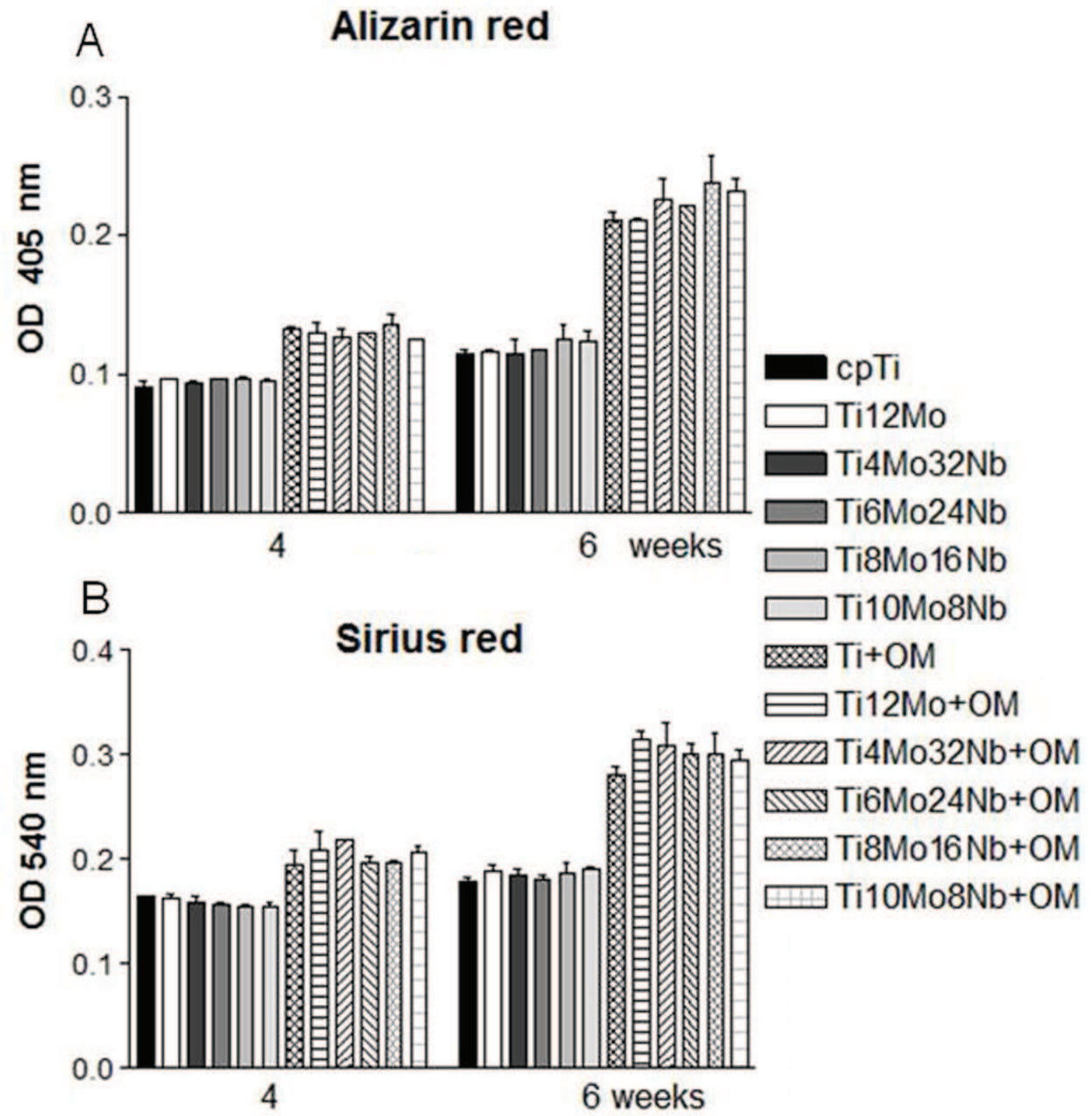


Fig. 5. Morphological features of RAW 264.7 macrophages stained with Alexa Fluor 488 phalloidin for actin labeling (A), and proliferation rate as assessed by MTT assay (B). The cells were grown in contact with cpTi and beta Ti-Mo-Nb alloys for $24 \mathrm{~h}$ and $48 \mathrm{~h}$ under standard (-LPS) or pro-inflammatory (+LPS) culture conditions. Data analysis was based on mean $\pm \operatorname{SD}(n=3)$. The scale bar corresponds to $20 \mu \mathrm{m}$ length.

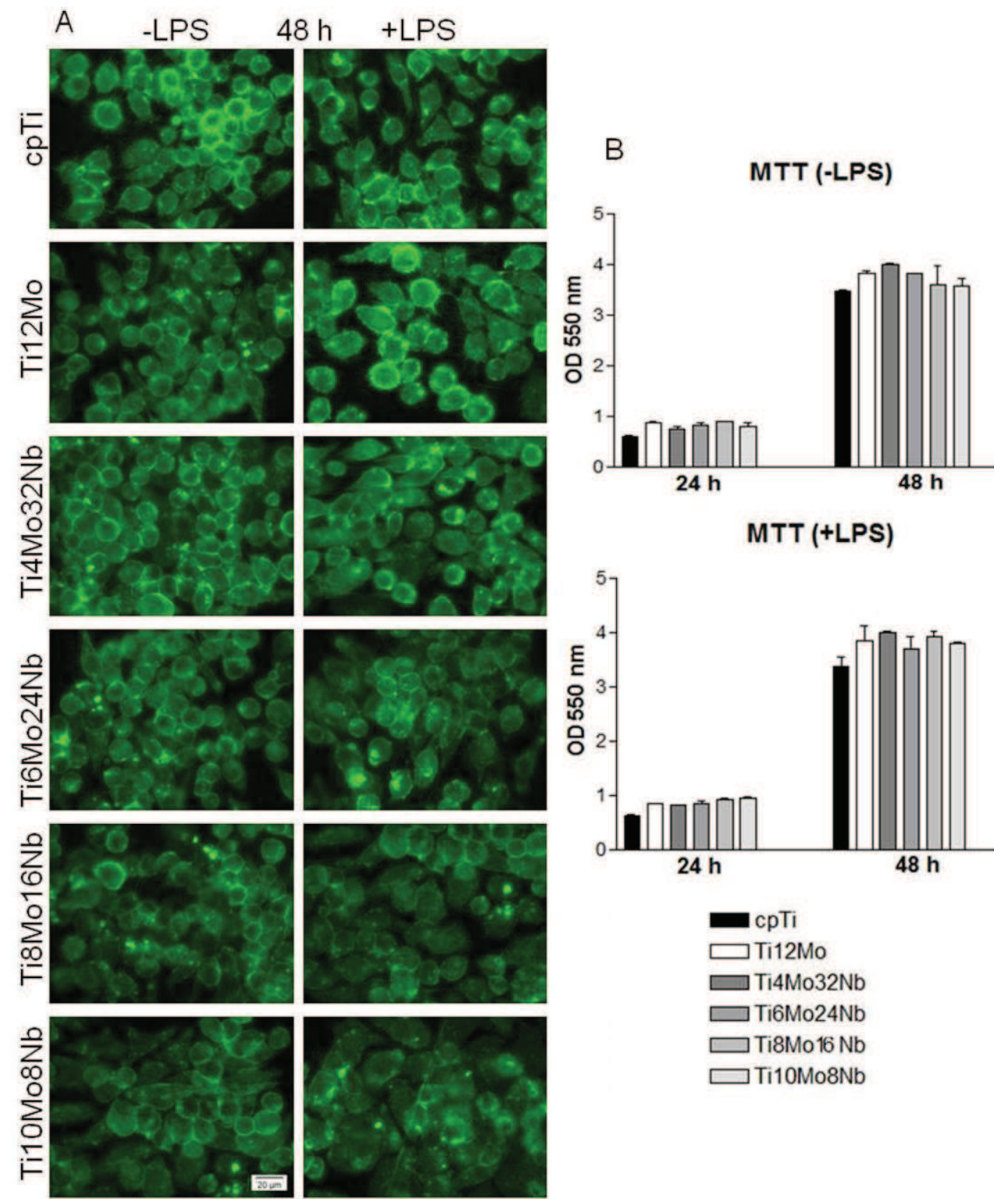


Fig. 6. The levels of cytokine/chemokines secreted into culture media after $24 \mathrm{~h}$ and $48 \mathrm{~h}$ culture of RAW 264.7 macrophages on tested samples under standard and LPS-stimulated conditions. Data are expressed as mean $\pm \mathrm{SD}(\mathrm{n}=3)$.
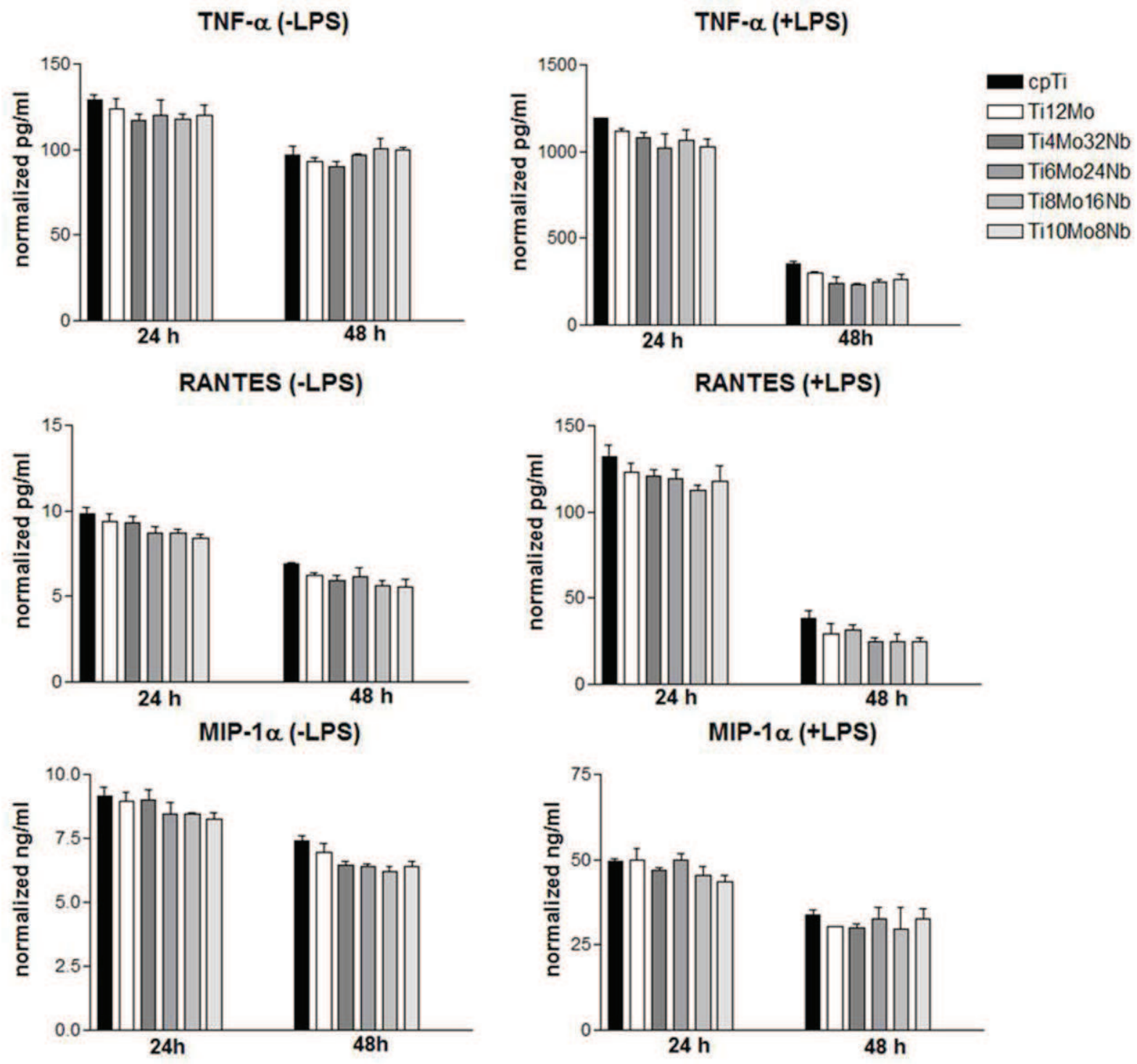


\section{Highlights}

- Ti-Mo-Nb compositions show a fully $\beta$-microstructural state by XRD analysis.

- Similar osteoblast growth and differentiation is displayed by $\beta-T i$ alloys and cpTi.

- Ti-Mo-Nb alloys elicit a slightly lower inflammatory response than cpTi. 